\title{
Design of Brake Regeneration Controller and Proton Exchange Membrane Fuel Cell Power Supply for a Robot
}

\author{
P. S. Pa, J. H. Shieh, and S. C. Chang
}

\begin{abstract}
This study presents a "design model for regenerative braking control" which will operate in collocation with a "Hydrogen-based Energy" module which in turn is constructed using "Proton Exchange Membrane (PEM) Fuel Cells and Solar Cells". These cells that provide a more efficient method of energy usage for a tripedal-robot product, permitting energy to be stored from the brake regeneration process, and providing access to a new energy source that is both environmentally-friendly and clean. The authors use Taguchi's Method to analyze the "Proton Exchange Membrane Fuel Cell Power Supply" and the "Time Ratio Control ( TRC ) method" Work Module for the Robot. A design model of regenerative braking control in electric motorcycles and an experimental identification is presented to achieve effectively a regenerative current. Simulation and experimental results are effective in tracking the regenerative current command. Evaluating the simulation results could provide valuable data to design and analyze prototypes of the tripedalrobot. The study assembled the proton exchange membrane fuel cell power supply module in the "Tripedal-Robot Product of Hydrogen-based Energy Module-Robot of Hydrogen-based Energy" and observes its operation state. It finds that the robot moved forward smoothly, and indicates that hydrogen can be used for the robot. The platform of the "Tripedal-Robot Product of Hydrogen-based Energy Module-Robot of Hydrogen-based Energy" will also become a design reference for such devices in the engineering and the manufacturing fields and should provide useful options and applications for the commercialization of different industrial robots.
\end{abstract}

Index Terms-Tripedal-robot, hydrogen-based energy, fuel cells, brake regeneration controller, manufacturing, model simulation.

\section{INTRODUCTION}

In the development of motion electric products, different computer simulation programs can be used in the design stage to predict performance. The simulation results will be used as the reference index for the purpose of raising performance levels. The calculation formula will allow higher precision to be obtained when measuring the performance of motor and control devices [1]. Making use of the brake regeneration device will transform kinetic energy into electrical energy, which will be stored in the electric cell for purposes of regeneration. This will increase the consecutive operational capacity of the device. The motor transforms the driving model into a generator model,

Manuscript received June 8, 2016; revised October 12, 2016.

The authors are with the Department of Digital Content Design and the Graduate School of Toy and Game Design at the National Taipei University of Education, Taiwan (e-mail: myhow@seed.net.tw.) which achieves the aim of brake regeneration without increasing the amount of hardware circuits [2]. Some uncertain factors of lead-acid batteries result in a larger margin, but lead-acid batteries are used extensively due to their low cost, mature technique, and the longer physical research history of the model. The lithium battery is highly priced, although it delivers a better performance. The rolling friction and air resistance effect from the dynamic performance of bodywork has been developed [3], [4]. The transmission system was driven directly using a stationary reduction gear ratio, or adopting variable speed gear of automatic transmission and continuously variable transmission (CVT). The transmission wheel torque and the rotational speed are thus definitively solved [5]. Using a higher battery of energy density is the solution to transforming the kinetic energy of a generator into electric energy stored in the battery, so as to increase the capacity for continuous operation. This method must put increase a charger into the motor, and design a new kind of electric circuit to regenerate electric energy through constantvoltage, constant -current, or pulsed charge. The principle of regenerative braking control can use a Boost DC-DC converter or a Buck-Boost Bi-directional DC-DC converter [2]. The regenerative circuit system uses a large volume and weight of transformers, and inductance will cause additional load energy exhaustion. The control method made use of a fuzzy control system, and uses velocity as a function to control brake regeneration [6], [7]. It is not necessary to use a charger, but doing so will also allow a regenerative circuit to be obtained. The regenerative circuit generates and fly to the power supply through the conversion principle of boost voltage and the method of Current Limit Control (CLC). Moreover, another regenerative control is operated with the Time Ratio Control ( TRC) of a chopper, which will also generate regenerative braking [8]. A characteristic of the software is that it can simulate digital signals, analog signals, and composites of both, a built-in feature of the model stitching (electric circuit, machinery, control system, etc.). The program interface involves the use of Saber-Sketch, Saber-Guide and Saber-Scope, which are used to design, simulate, and analyze respectively. The program uses a variable nonlinear normal differential equation to solve problems. Every composition within the software system written to form the module by MAST high-level language is used to describe the component model. Thus, it has a superior ability to simulate and analyze diversified nonlinear problems. However, although the above software package has been extensively used in electrical engineering, the selling price is too high; thus, the cost of the development 
has increased [9], [10]. Matlab provides several hundreds of built-in mathematical libraries. These function formulas can solve matrix algebra, plural counting, linear systems, differential equations, signal treatment, optimization, nonlinear systems, and many other different scientific operations [11]. Matlab thus makes it is easy to design simulation programs for dynamic systems and is effective in simulating the characteristics of linear and nonlinear systems by means of graphics and intuitive program design of Simulink [12], [13]. The ability to move efficiently in complex environments is a key property of animals. The interactions have mainly been in one direction, with robotics taking inspiration from biology in terms of morphology, mode of locomotion, and/or control mechanisms. In particular, many robot structures are directly inspired by animal morphology: snake robots, quadruped robots and humanoid ones. Increasingly, robotics are now giving something back to biology, they are being used as scientific tools to test biological hypotheses. The focus of this article is on the aspect of control, in particular with respect to rhythm generation by central pattern generators (CPGs). Basic rhythmic movements in animals are generated by a network of neurons in the spinal cord called the Central Pattern Generators. CPGs have been studied extensively and our understanding of them is improving. A model of the CPGs was proposed by Cohen in the early 1980s and subsequently this model was successfully implemented to generate locomotion patterns for robots with or without legs. CPGs are neural circuits found in both vertebrate and invertebrate animals that can produce rhythmic patterns of neural activity without receiving rhythmic input. The term central indicates that sensory feedback (from the peripheral nervous system) is not needed to generate the rhythms [1416]. A study applies CPG to easily parameterize and synchronize a set of open loop trajectories. In the future, the authors will also use CPG to close the sensor/actuator loop. The CPG that drives a hip joint consists of a fully connected network of four phase-coupled oscillators, each oscillator driving one hip joint [17]. CPGs underlie many fundamental rhythmic activities such as chewing, breathing, and digesting. They are also the fundamental building blocks for the locomotor neural circuits both in vertebrate and invertebrate animals. Depending on the phenomena under study, CPG models have been designed at several levels of abstraction from detailed biophysical models, to connectionist models and the abstract systems of coupled oscillators. In some cases, the CPG models have been coupled to biomechanical simulation of a body, in which case they are called neuro-mechanical models and robots with continuously rotating legs, or legged but hexapedal robots like iSprawl. The study describes legged, quadruped robots by their general leg design, degrees of freedom (DOF) per leg, and the type of actuation used. Legged robot systems with a prismatic leg design apply a linear sliding or telescopic mechanism, extending and shortening the leg along a line between the foot and hip joint. A single, active DOF presents a balanced solution between robot weight, complexity, and gait versatility. Instead of a second active joint per leg, a lock-and-release mechanism can be implemented. This bends the knees through passive leg dynamics, and provides foot ground clearance. Advances in the fundamental understanding of the functioning of CPGs will not only help biology and robotics, but may also have an impact in medicine, with possible contributions in the long term to the design of therapy (e.g. using electrical stimulation) for patients with spinal cord injury [18]-[21].

The known fuel cells can be divided into six categories: the Proton Exchange Membrane (PEM); Direct-Methanol (DM); Alkaline; Phosphoric Acid (PA); Molten Carbonate (MC) and Solid Oxide (SO) Fuel Cells depending on the electrolyte used. The PEM and (DM) Fuel Cells both operate at room temperature, have similar properties and are feasible power sources for portable electrical equipment and home appliances [22]. The PEM Fuel Cell is superior to the (DM) Fuel Cell in being more energy efficient, uses Hydrogen as a fuel and there is no production of poisonous carbon monoxide. The (DM) Fuel Cell also requires fuel purification. The PEM Fuel Cell is easy to maintain, has a longer life and is more suitable for toys [23]. Fuel cells can be arranged in modules and this makes it easy to meet different power demands. There is a range of different business opportunities for fuel cells, such as power sources for $3 \mathrm{C}$ electronic devices, transportation facilities, small power generation for home use and larger sized power plants for communities. A recent development in Japan is the use of fuel cells in mobile charging stations for $3 \mathrm{C}$ products. It is anticipated that fuel cells will play an important role in the future [24]-[26].

In 1980, Miyazaki \& Arimoto applied the Singular Perturbation method to categorize the dynamic behaviors of the biped robot into the fast mode and slow mode, and designed the controller based on the method. In 1986, Railbert published his book The Balance of the Robot with Feet, which is regarded as the most pioneering and contributive research for all oil-pressure-driven robot with one, two, or four feet [27]. In 1995, T. Irie, T. Hirose, and K. Itoh adopted the genetic algorithm in the walking trajectory calculation of the tripedal robots, and the result was used in a tripedal robot driven hydraulically [28], [29]. Engineers in many countries of the world have recently begun to focus on the use of advanced and intelligent industrial robots. In the past, the application of a robot system was usually for manufacture, and few were used in daily life [30], [31]. In 2000, Yun-Jung Lee and Shigeo Hirose conducted a simulation for the mime-detected quadped robot concerning how to move the remaining three walking legs to complete the mission while one walking leg was broken. Since the type of tripedal walking robot was derived from the quadped robot with one incapacitated walking leg, the remaining three walking legs were asymmetric. The walking mode in the research adopted the kick-and-swing walking method to complete the movement [32]. In 2001, Sylvain Martel et al. minimized the tripedal robot and designed a tripedal robot made by piezoelectric ceramics. The size of the robot was similar to a coin, and its movement in theory could reach up to $4000 \mathrm{step} / \mathrm{sec}$ [33].

This study demonstrates two different modules to save energy from "brake regeneration energy" and to power a new energy source from "Proton Exchange Membrane (PEM) Fuel Cells and Solar Cells" that provides a new energy source and a that is environmental-friendly and clean. In the current study, the authors use the software of Matlab 
and Simulink to develop the models of different portions of a tripedal-robot, and then take them into integration and simulation. The acceleration performance, the highest speed, energy dissipation, and the results of simulation of the dynamic and transient state can be displayed in real-time or stored for providing analysis following simulation. The authors make use of the Hall sensor and optical encoder to design the regenerative current controller by using the feedback position and velocity control. One must approve the performance of the regeneration controller after checking against the simulation results and practical measurement data. This study is also aimed at the collocation of the module of the "Hydrogen-based Energy" realized upon the "Proton Exchange Membrane (PEM) Fuel Cells" and "Solar Cells" that provide a more efficient method of energy usage for tripedal-robot products, and can be powered by a new energy source that is environmentallyfriendly and clean. The authors use Taguchi's Method to analyze the "Proton Exchange Membrane Fuel Cell Power Supply and Work Module for Robot". Taguchi's Method was developed by Dr. Taguchi and is a scientifically disciplined mechanism for evaluating and implementing improvements in products, processes, materials, equipment, and facilities. These improvements are aimed at improving the desired characteristics and simultaneously reducing the number of defects by studying the key variables controlling the process and optimizing the procedures or design to yield the best results [34]. The energy consumed by a fuel cell is "Hydrogen-based Energy", which lies in converting the chemical energy of Hydrogen and Oxygen into electric power by using the characteristic of the fuel cell, so as to provide features of high efficiency, simple principles, low pollution and low noise. If such fuel cell is used with the electric power from "solar energy" to electrolyze water and produce Hydrogen and Oxygen, the "Hydrogen-based Energy" can be used in a circle. This research not only effectively raises the commercial potential for hydrogenpowered industrial robots for the engineering and the manufacturing fields, but also makes a contribution to academic science and environmental education.

\section{EXPERIMENTAL METHOD}

\section{A. Model Design and Performance Identification in Regenerative Brake Control}

The experimental set-up is shown in Fig. 1. The experimental equipment of brake regeneration includes a computer, a control interface card, a motor secondary driver, a DC brushless motor, and a permanent magnet synchronous motor. Using a computer as a controller for composing the control program is easy and convenient. It also meets the requirements of enabling the operational speed to be controlled by computer. Thus, the experimental results will allow identification of control theory. Using the function of self-made control interfaces will allow the motor to produce PWM signals. In addition, it can also be used to measure electric current, motor position, velocity, and post driving protection etc. The main function of the control interface card is that it produces a PWM signal according to the control instruction, and the other function also includes the measurement of three phase current and position signal of the motor. The power switch (MOSFET) of the secondary driver will provide the electric power for the motor or the brake according to the PWM signal. The motor is driven to rotate when the experiment begins, and stops rotating after the rotational speed reaches more than 500rpm. At this time, the motor and the flywheel kept running until it reached a state of inertia, and the rotational speed gradually decreased. The Hall sensor or Decoder picked a position input signal of the turning-angle and counted the rotational speed. Picking the data of the electric current and brake force of torsion meter formed an analysis of the experimental results. The experimental parameters included no command of brake regeneration, $5 \mathrm{~A}$ and $10 \mathrm{~A}$ of command of brake regeneration, from $5 \mathrm{~A}$ increasing to $10 \mathrm{~A}$ of command of brake regeneration, simulation three phase electric current of DC motor, electric voltage, rotational speed, and a variety of electric currents for brake regeneration.

\section{B. Proton Exchange Membrane Fuel Cell Power Supply and Work Module}

TABLE I (A): EXPERIMENTAL CONTROL FACTOR AND OPERATION TIME

\begin{tabular}{|l|l|l|l|l|}
\hline Factor & Description & Level 1 & Level 2 & Unit \\
\hline A & Volume of The Gas Tank & 1021.88 & 15377.19 & $\mathrm{~mm}^{3}$ \\
\hline B & Electric Load & 11.90 & 6.17 & $\Omega$ \\
\hline C & Initial Pressure Value of The Gas Tank & 0.388 & 0.197 & $\mathrm{~N} / \mathrm{m}^{2}$ \\
\hline
\end{tabular}

TABLE I (B): EXPERIMENTAL CONTROL AND LEVEL ORTHOGONAL RRAY OF OPERATION TIME

\begin{tabular}{|c|c|c|c|}
\hline $\begin{array}{l}\text { Experiment } \\
\text { Sequence }\end{array}$ & $\begin{array}{l}\text { A } \\
\text { Volume of The Gas } \\
\text { Tank }\left(\mathrm{mm}^{3}\right)\end{array}$ & $\begin{array}{l}\text { B } \\
\text { Electric } \quad \text { Load } \\
(\Omega)\end{array}$ & $\begin{array}{l}\text { C } \\
\text { Initial Pressure- Value of } \\
\text { The Gas Tank }\left(\mathrm{N} / \mathrm{m}^{2}\right)\end{array}$ \\
\hline 1 & $\begin{array}{l}10198.82 \\
\mathrm{~A} 1\end{array}$ & $\begin{array}{l}11.81 \\
\mathrm{~B} 1\end{array}$ & $\begin{array}{l}0.397 \\
\mathrm{C} 1\end{array}$ \\
\hline 2 & $\begin{array}{l}10182.71 \\
\mathrm{~A} 1\end{array}$ & $\begin{array}{l}6.10 \\
\mathrm{~B} 2\end{array}$ & $\begin{array}{l}0.179 \\
\mathrm{C} 2\end{array}$ \\
\hline 3 & $\begin{array}{l}15259.72 \\
\text { A2 }\end{array}$ & $\begin{array}{l}11.67 \\
\mathrm{~B} 1\end{array}$ & $\begin{array}{l}0.198 \\
\mathrm{C} 2 \\
\end{array}$ \\
\hline 4 & $\begin{array}{l}15297.36 \\
\text { A2 }\end{array}$ & $\begin{array}{l}6.31 \\
\mathrm{~B} 2\end{array}$ & $\begin{array}{l}0.401 \\
\mathrm{C} 1\end{array}$ \\
\hline
\end{tabular}

In the study, Taguchi's Method was implemented in the "Proton Exchange Membrane Fuel Cell Power Supply and Work Module for tripedal-robot product". Therein, the "operation time", $t$, is the quality characteristic and the time unit is second. Further, the appropriate orthogonal array is selected according to the control factors and levels determined upon the experimental demands. Therefore, the optimum parameter can be derived through analyses of the quality characteristics, standard deviation, and the largerthe-better $\mathrm{S} / \mathrm{N}$ ratio with respect to the control factors. The study uses the volume of the gas tank, the electric load, and the initial pressure value of the gas tank as the control experimental factors for measuring the operation time of the Power Supply and Work Module in accordance with a twolevel-three-factor design of experiments. Thus the module meeting the experimental demands are re-planned with respect to the volume of the gas tank, the electric load, and the initial pressure value of the gas tank of the "Proton Exchange Membrane Fuel Cell Power Supply and Work Module for tripedal-robot product". After calculation, the 
control factors and levels of the designed module meeting the experimental demands are listed in Table 1 (a) and can be made as the experimental factor-and-level orthogonal array of the operation time of the Power Supply and Work Module as in Table I (b) from $\mathrm{L}_{4}\left(2^{3}\right)$ orthogonal array reference to the experimental factor arrangement of the Taguchi Method.

\section{RESULTS AND DISCUSSION}

\section{A. Model Simulation and Measurement Analysis of Design of Regenerative Brake Control}

The DC brushless motor is used with the three Hall sensor to detect the current position of the motor's rotation. Six power-switch controls drive the voltage vector which then makes the motor produce the control of the change in direction. We assume the period of PWM is $T$, one can analyze the situation of steady state for the time ratio control (TRC) of the regeneration brake through cutting over the $\mathrm{H}$ Bridge switch of each area. The model is constructed from a mathematical analysis of the DC brushless motor.

Let $\left(i_{a}-i_{b}\right)=I_{a b}$ then:

$$
L_{s} \frac{d}{d t} I_{a b}+R \cdot I_{a b}+2 k_{e} \omega \cdot=\left(v_{a g}-v_{b g}\right)=v_{a b}
$$

thus

1) The area of power storage $(0 \leq t \leq \alpha T)$

$$
L_{s} \frac{d I_{a b}}{d t}+R \cdot I_{a b}+2 k_{e} \omega=0
$$

2) The area of power regeneration $(\alpha T \leq t \leq T)$

$$
L_{s} \frac{d I_{a b}}{d t}+R \cdot I_{a b}+2 k_{e} \omega=V
$$

The control's low written to:

$$
V_{a b}=2 k_{e} \omega+k_{p} \cdot\left(I^{*}-I_{a b}\right)+k_{i} \int_{0}^{t}\left(I^{*}-I_{a b}\right) d \xi
$$

The mathematics mold is the same as the permanent electromagnetic synchro-control motor when responding to the electromotive force with the sine wave. The mathematics mold is:

$\frac{d}{d t}\left\{\begin{array}{l}i_{A} \\ i_{B} \\ i_{C}\end{array}\right\}=-\left[\begin{array}{ccc}R / L & 0 & 0 \\ 0 & R / L & 0 \\ 0 & 0 & R / L\end{array} \mid\left\{\begin{array}{l}i_{A} \\ i_{B} \\ i_{C}\end{array}\right\}+\frac{1}{L}\left\{\begin{array}{l}v_{A} \\ v_{B} \\ v_{C}\end{array}\right\}+\frac{K N}{L} \omega\left\{\begin{array}{c}\sin (N \theta) \\ \sin (N \theta-2 \pi / 3) \\ \sin (N \theta+2 \pi / 3)\end{array}\right\}\right.$

The motor's dynamic state equation of a stator is converted to the coordinates of a rotor when making use of the Park Transform.

$\frac{d}{d t}\left\{\begin{array}{l}i_{d} \\ i_{q}\end{array}\right\}=\left[\begin{array}{cc}-R / L & N \omega \\ -N \omega & -R / L\end{array}\right]\left\{\begin{array}{l}i_{d} \\ i_{q}\end{array}\right\}+\frac{1}{L}\left\{\begin{array}{l}v_{d} \\ v_{q}\end{array}\right\}-\frac{K N}{L} \omega\left\{\begin{array}{l}0 \\ 1\end{array}\right\}(6)$

Using nonlinear state feedback makes the system linear, $I$ is the value of electric current, the control law is:

$$
\begin{gathered}
u_{d}=k_{p d} \cdot\left(i_{d}^{*}-i_{d}\right)+k_{i d} \int_{0}^{t}\left(i_{d}^{*}-i_{d}\right) d \xi \\
u_{q}=k_{p q} \cdot\left(i_{q}^{*}-i_{q}\right)+k_{i q} \int_{0}^{t}\left(i_{q}^{*}-i_{q}\right) d \xi
\end{gathered}
$$

$$
\begin{gathered}
G_{d}(s)=\frac{i_{d}(s)}{i_{d}^{*}(s)}=\frac{k_{p d} s+k_{i d}}{L s^{2}+\left(R+k_{p d}\right) s+k_{i d}} \\
G_{q}(s)=\frac{i_{q}(s)}{i_{q}^{*}(s)}=\frac{k_{p q} s+k_{i q}}{L s^{2}+\left(R+k_{p q}\right) s+k_{i q}}
\end{gathered}
$$

The gain value of the controller is obtained after assigning the damping coefficient $\zeta$ and the natural frequency $\omega_{n}$ of the characteristic equation

$$
\begin{gathered}
k_{p d}=k_{p q}=k_{p}=L \cdot 2 \zeta \omega_{n}-R \\
k_{i d}=k_{i q}=k_{i}=L \cdot \omega_{n}^{2}
\end{gathered}
$$

The control's law is:

$$
\begin{gathered}
V_{d}=-L N \omega \cdot i_{q}+k_{p} \cdot\left(i_{d}^{*}-i_{d}\right)+k_{i} \int_{0}^{t}\left(i_{d}^{*}-i_{d}\right) d \xi \\
V_{q}=K N \omega+L N \omega \cdot i_{d}+k_{p} \cdot\left(i_{q}^{*}-i_{q}\right)+k_{i} \int_{0}^{t}\left(i_{q}^{*}-i_{q}\right) d \xi(14)
\end{gathered}
$$

One obtains the regeneration electric current through controlling the three power switch of the post-drive circuit. It is not easy to produce enough regenerative electric current when executing cutting over to use as the symmetry signal of SVPWM, thus the dissymmetry signal of SVPWM is used to produce the electric voltage of the space vector. For the purpose of realizing brake regeneration control, the experiment using the flywheel and brake devices replaced the load of the car-body. The motor stopped when it rotated over 500rpm, at this time, the motor and the flywheel kept on revolving until reaching a state of inertia and appeared gradually to lower its speed. It inputted the signal and calculated the rotational speed by picking the motor's shiftangle position following the Hall sensor or Encode. The brake experiment according to the brake regeneration controller calculates the motor's driving signal and controls the switch of the driver, which causes the motor to produce the brake regeneration current. The experimental parameters include none command of brake regeneration, 5A and 10A of command of brake regeneration, from $5 \mathrm{~A}$ increasing to $10 \mathrm{~A}$ of command of brake regeneration, simulation of the three phases of electric current of DC motor, electric voltage, rotational speed, and variety of electric current of the brake regeneration. The command of brake regeneration, data of electric current and rotational speed will be analyzed from the experimental results from the actual measurements. The experiment adds the flywheel to DC brushless of the electric motorcycle. The data of position and velocity are obtained from the Encoder and Hall sensor. It must consider the parameters $\left(J_{1} \cdot B_{1} \cdot C_{1}\right)$ of the moment of inertia of the flywheel and butt joint to the motor to add to the load of the motor, thus the practical angular velocity and angular acceleration of motor is obtained.

$$
\begin{array}{r}
\tau_{l}=I_{\text {flywheel }} \dot{\omega}+J_{1} \dot{\omega}+B_{1} \omega+C_{1} \operatorname{sgn}(\omega) \\
\dot{\omega}=\left(-B \omega-C \operatorname{sgn}(\omega)-\tau_{l}+T_{e}\right) / J
\end{array}
$$

Obtaining the system transformation function 


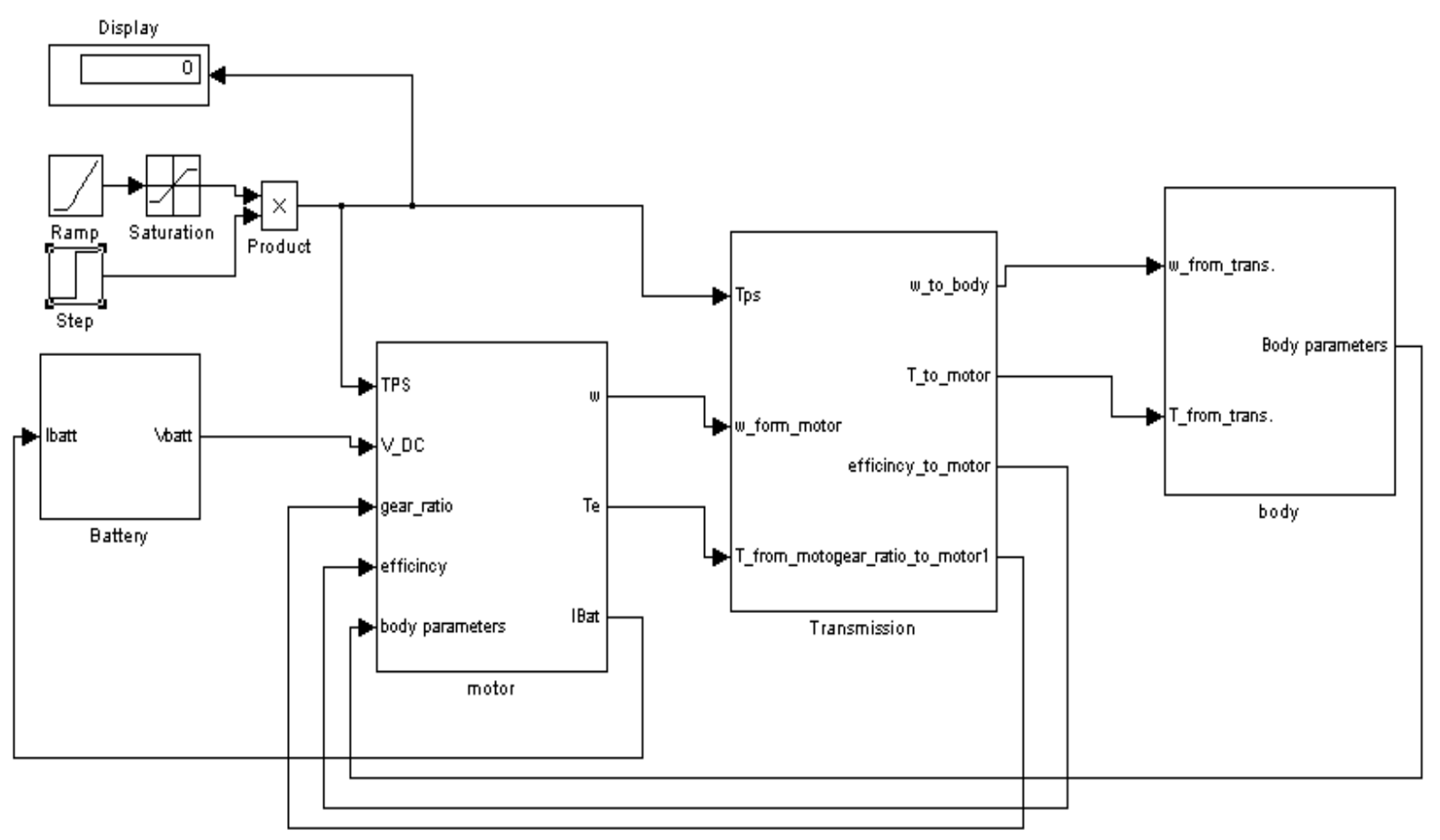

Obtained.

Fig. 1. Integration-model of the electrical vehicle with Simulink.

$$
\dot{\omega}=\left(\begin{array}{l}
T_{e}-B \omega-C \operatorname{sgn}(\omega) \\
-B_{1} \omega-C_{1} \operatorname{sgn}(\omega)
\end{array}\right) /\left(J+J_{1}+I_{\text {flywheel }}\right)
$$

Velocity $\omega$ obtained following $\omega$ integral calculus

As deduced above, the obtaining of the simulation requirement of the motor of the electricity equation and mechanical running equation is applicable to establishing in the model of Simulink. Aiming at using the Hall Sensor as the regenerative braking control, one can obtain the simulation and experimental results and discussions. Adding the design PI electric current controller to the model of the controller, setting up the control parameters $\zeta=20$, $\omega_{n}=200 H z$. It is worth noticing that the characteristic of damping coefficient of regenerative braking control and the characteristic of damping coefficient of driving motor are contrary to each other. The response of the regenerative current control is to slow down if the damping coefficient of regenerative braking control is reduced. On the contrary, the response of the regenerative current control is rapid if the damping coefficient of regenerative braking control is increased. Using Hall Sensor, one assumes the rotational speed of motor is 500rpm, the command of brake simulation is 5A. Fig. 2 shows that the simulated relationship of the variation of three phase electric current and voltage of the motor and the variation of every angle, when phase voltage positively produced a negative current, thus caused negative torque to be applied to the brakes of the motor, also creating a regenerative electric current.

Fig. 3 shows that the simulation relationship of the variation of three phase electric current and voltage of the motor and the variation of every angle, when phase voltage is positive it produced a negative current, thus causing negative torque to be applied to the brakes of the motor, also creating the regenerative electric current.
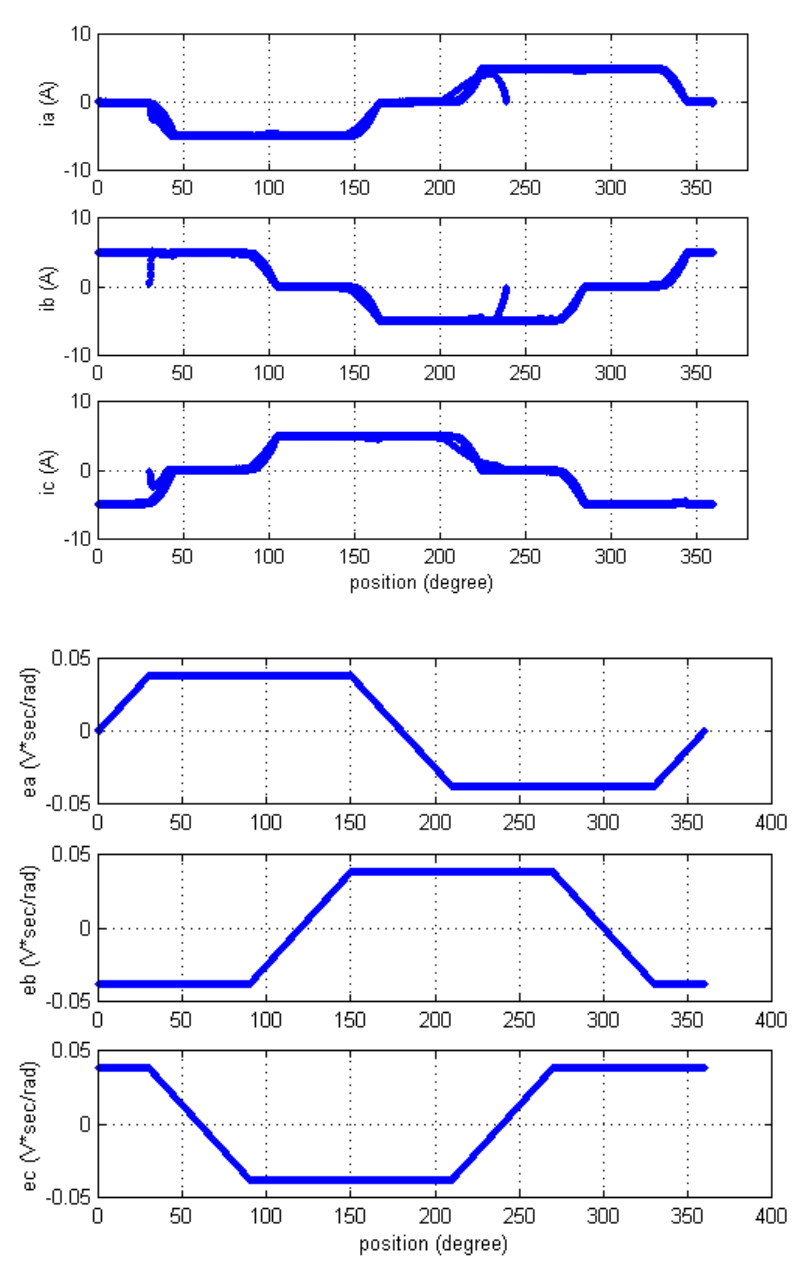

Fig. 2. Simulation of regenerative current 5A for relationship of degree and three - phase current of motor (left Figure); Simulation of regenerative current $5 \mathrm{~A}$ for relationship of degree and three - phase voltage of motor (right Figure). 

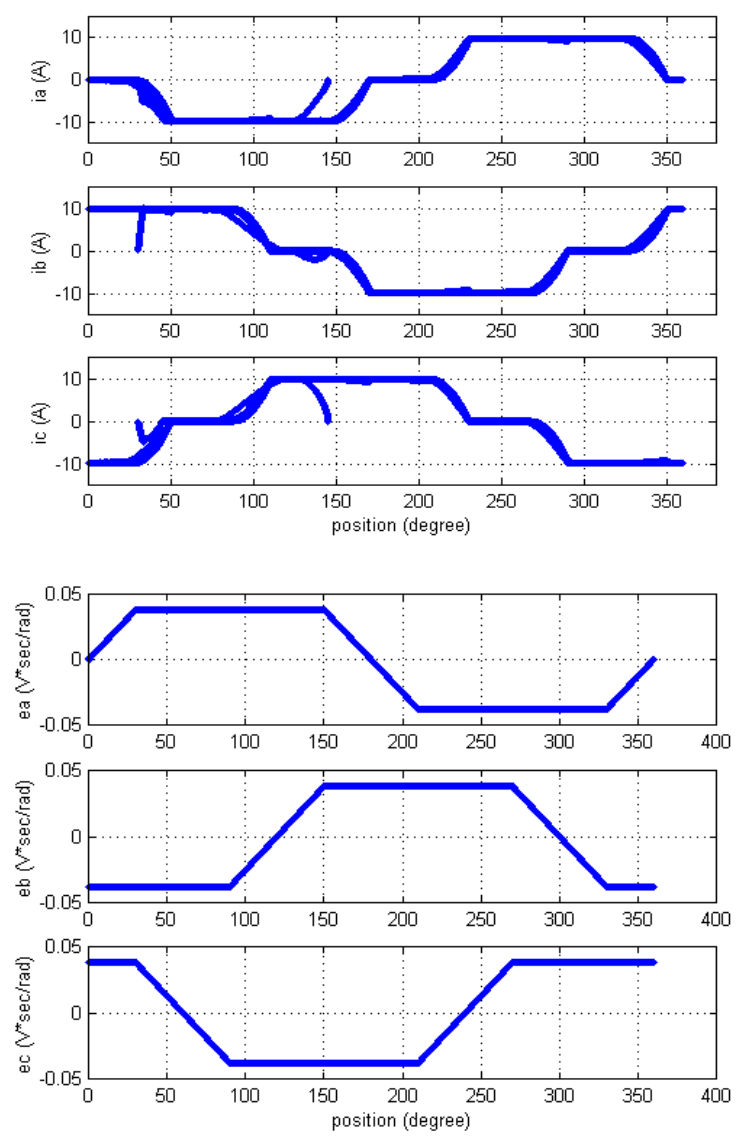

Fig. 3. Simulation of regenerative current 10A for relationship of degree and three - phase current of motor (top figure); Simulation of regenerative current $10 \mathrm{~A}$ for relationship of degree and three - phase voltage of motor (right figure).
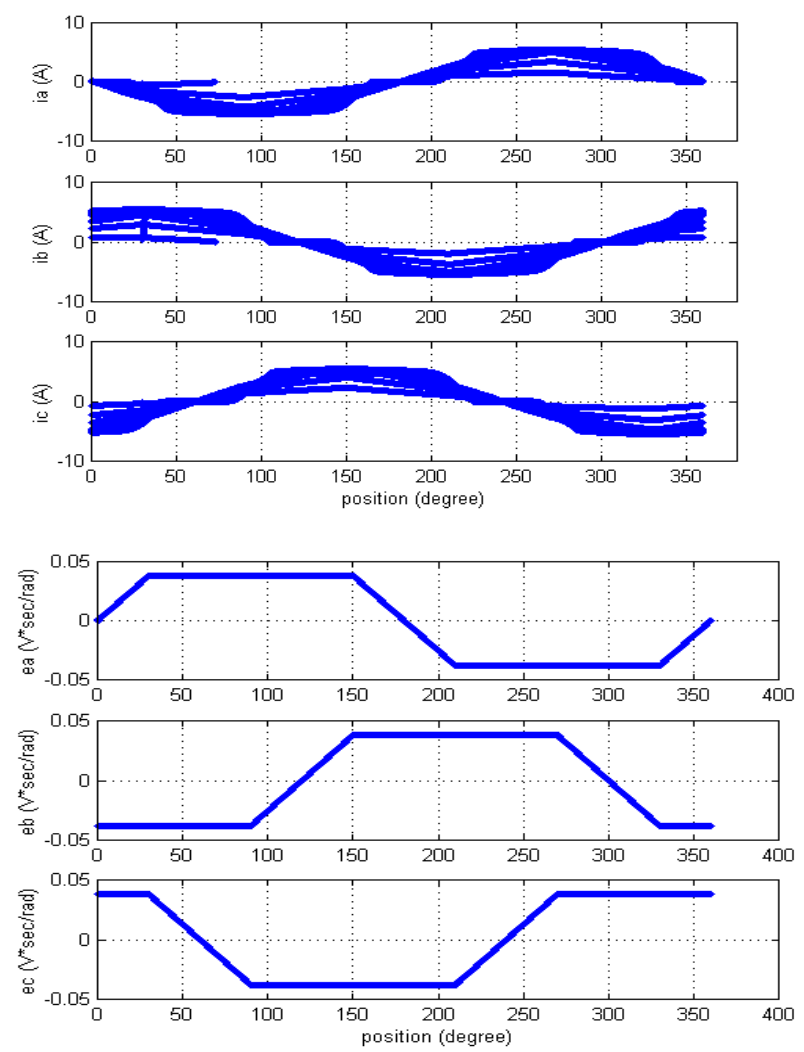

Fig. 4. Simulation of regenerative current $5 \mathrm{~A}$ following resistance increase for relationship of degree and three - phase current of motor (left figure); Simulation of regenerative current $5 \mathrm{~A}$ after resistance increased for relationship of degree and the three - phase voltage of motor (right figure) rotation, torque, and time.
The simulation results of the influence aimed at the current sensor and electric wire, producing a resistance value of about $0.1 \Omega$, respectively show the simulation of the brake regenerative current 5A and 10A (see Fig. 4 and 5).
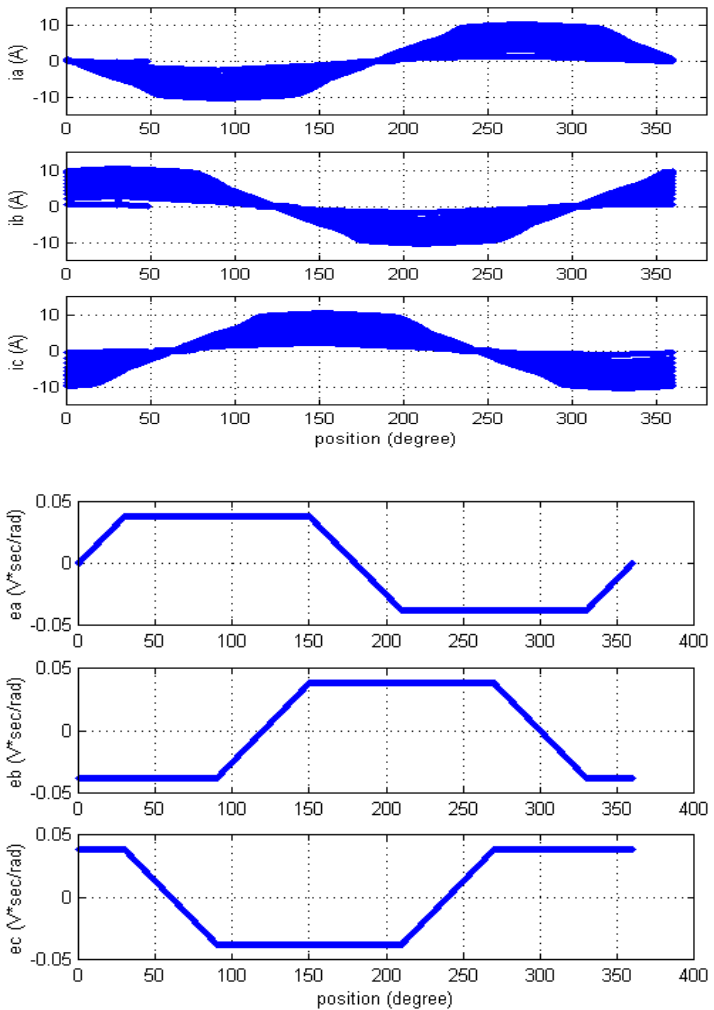

Fig. 5. Simulation of regenerative current $10 \mathrm{~A}$ after resistance increased for relationship of degree and three - phase current of motor (top figure); Simulation of regenerative current $10 \mathrm{~A}$ after resistance increased fo relationship of degree and three - phase voltage of the motor (right figure).
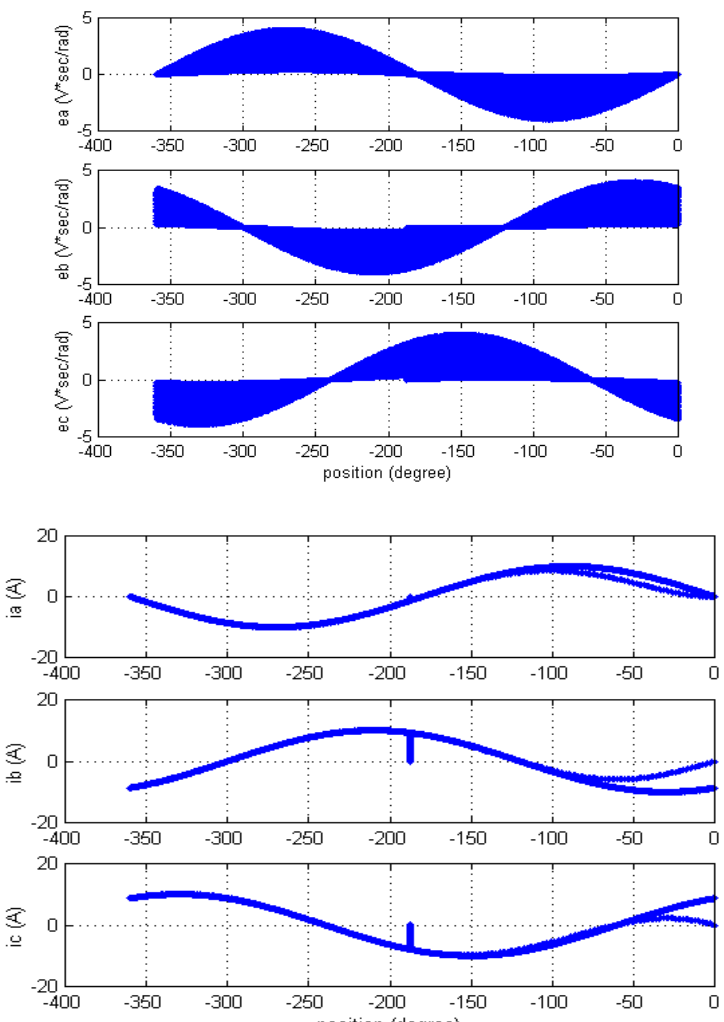

Fig. 6. Simulation of regenerative control with encoder for relationship of degree and three - phase voltage of motor (left figure); Simulation of regenerative control with encoder for relationship of degree and three phase current of motor (right figure). 
The simulation results are the same as the experimental results. The regenerative current will not be produced at a low speed. Using Encoder and SVPWM control, assuming the rotational speed and the command of brake simulation of the motor is $1000 \mathrm{rpm}$ and 10A, Figure 6 shows the simulation relationship of the variation in three - phase electric current and voltage of the motor and the variation of every angle. One assumes the response electromotive force is sine wave, the simulation results drawn as an axis of abscissae of the angle from the starting brake to the rotational speed slowed down to $0 \mathrm{rpm}$. The voltage changed from large to small, and the electric current dropped to zero since it could not be produced. It produced a negative current when the phase voltage was positive from the simulation results, thus it obtained a negative torque and forced the motor brake, also producing the regenerative current.

\section{B. Parameters Assessment of PEM Fuel Cell on Platform}

\section{1) Analysis of factors of quality characteristics}

The point of the analysis on the factors of quality characteristics is to calculate the resultant effects that the varied control factors cause to the quality characteristics so as to analyze and estimate the factor arrangement performing the optimum quality characteristics. The Factor Response (Level 1: $\mathrm{A}=3432.10, \mathrm{~B}=5017.50, \mathrm{C}=3852.90$; Level 2: $\mathrm{A}=4356.90, \mathrm{~B}=2772.80, \mathrm{C}=3935.20$ ) and Figure 7(a) of the quality characteristic can be made according to the experimental data. From Figure 7(a), one obtained: When the factors of $\mathrm{A}$ and $\mathrm{C}$ are adjusted from Level 1 to Level 2, the quality characteristics thereof present positive effects. That is, when the volume of the gas tank is increased and the initial pressure value of the gas tank is reduced, the operation time is increased. When the factor of B is adjusted from Level 1 to Level 2, the quality characteristics thereof present negative effects. That is, when the electric load is realized as to solar motor fans, the operation time is decreased. By observing the slopes of the three factors in Figure 7(a) it is learned that the B factor possesses the largest slope, which means the B factor (electric load) brings the greatest influence to the quality characteristics. And the $\mathrm{C}$ factor (the initial pressure value in the gas tank) has the smallest slope. Through the above analyses, it is evaluated that the factor combination performing the best quality characteristics is $\mathrm{A} 2 \mathrm{~B} 1 \mathrm{C} 2$.

\section{2) Analysis of factors of standard deviation}

The point of the analysis on the factors of standard deviation is to calculate the resultant effects that the varied level factors cause to the quality characteristic, namely the stability of the quality characteristic. The higher standard deviation indicates less stability of the resultant products. The Factor Response (Level 1: $\mathrm{A}=291.39, \mathrm{~B}=262.83$, $\mathrm{C}=213.37$; Level 2: $\mathrm{A}=275.03, \mathrm{~B}=302.17, \mathrm{C}=346.12$ ) and Fig. 7(b) of the quality characteristic can be made according to the experimental data. From Fig. 7(b), one obtained: When the factors of $\mathrm{B}$ and $\mathrm{C}$ are adjusted from Level 1 to Level 2, the variation is increased. That is, when the electric load is added to two solar motor fans to form one solar motor fan, and the initial pressure value of the gas tank is reduced, the stability of the quality characteristics is decreased. When the factor of A is adjusted from Level 1 to Level 2, the variation is decreased. That is, when the volume of the gas tank is increased, the stability of the quality characteristics is increased. By observing the slopes of the factors in the Figure, it is learned that the initial pressure value of the gas tank ( $\mathrm{C}$ factor) brings the greatest influence to the stability. Through the above analyses, it is evaluated that the factor combination performing the least variation is A2B1C1.

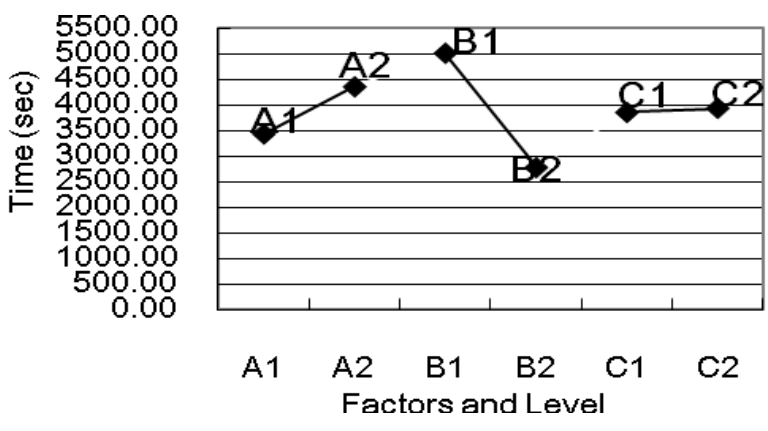

(a) Factor response graph of quality characteristic.

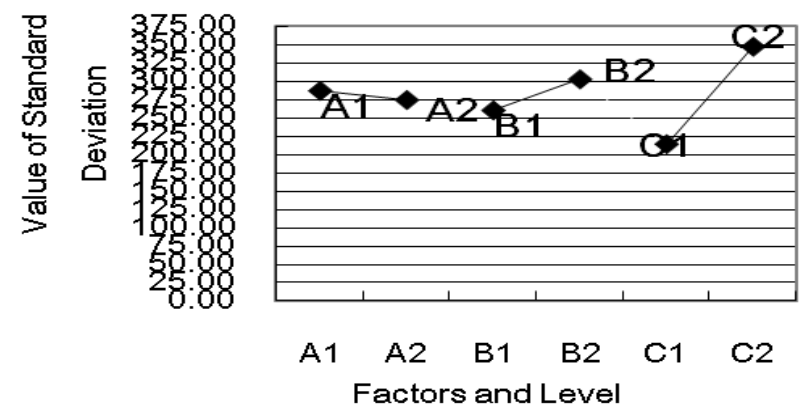

(b) Factor response graph of standard deviation factor.

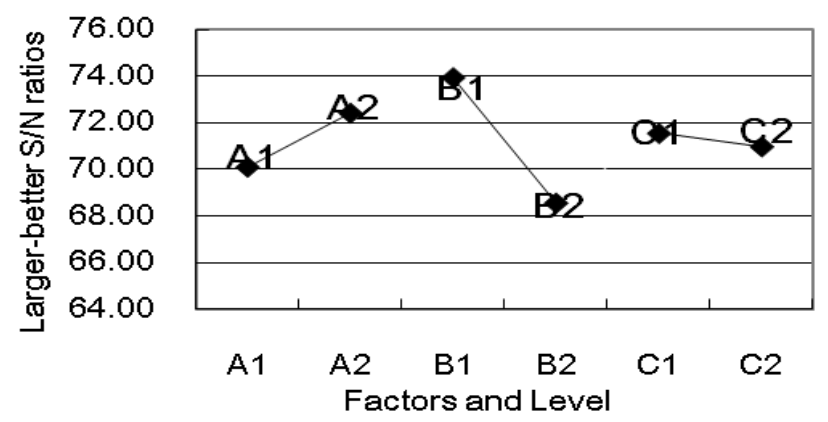

(c) Factor respons of larger-better $\mathrm{S} / \mathrm{N}$ ratios.

Fig. 7. Actor response graph of quality characteristic, standard deviation factor, and larger-better $\mathrm{S} / \mathrm{N}$ ratios in experiments of operation time of the power supply and work module.

\section{3) Analysis on $S / N$ ratio}

The Signal/Noise Ratio (S/N Ratio) is to integrate the optimal quality characteristics and the least variation into a single objective Since two optimal parameter combinations, $\mathrm{A} 2 \mathrm{~B} 1 \mathrm{C} 2$ and $\mathrm{A} 2 \mathrm{~B} 1 \mathrm{C} 1$ are derived through the analyses of the quality characteristic and the standard deviation factor; the analysis of the $\mathrm{S} / \mathrm{N}$ ratio is implemented to determine the optimal parameter combination. As the ideal function of the quality characteristic in the study is the larger the better, the "larger-better S/N ratio" is used to conduct data processing, so as to derive the larger-better $\mathrm{S} / \mathrm{N}$ ratios of the experiments as shown in Fig. 7 (c). The results are further made into the table and graph of the Factor Responses 
(Level 1: $\mathrm{A}=71.09, \mathrm{~B}=72.98, \mathrm{C}=71.67$; Level 2: $\mathrm{A}=72.472$, $\mathrm{B}=68.77, \mathrm{C}=71.01$ ) of the larger-the-better $\mathrm{S} / \mathrm{N}$ ratios. From Fig. 7 (c), one obtained: When the factors of $\mathrm{B}$ and $\mathrm{C}$ are adjusted from Level 1 to Level 2, the $\mathrm{S} / \mathrm{N}$ ratio is decreased. That is, when the electric load is added to two solar motor fans from one solar motor fan, and the initial pressure value of the gas tank is reduced, the data of the larger-the-better $\mathrm{S} / \mathrm{N}$ ratio are degenerated, which also means the quality characteristic is decreased and the operation time is reduced. When the factor of $\mathrm{A}$ is adjusted from Level 1 to Level 2, the $\mathrm{S} / \mathrm{N}$ ratio is increased. That is, when the volume of the gas tank is increased, the operation time is increased. By observing the slopes of the factors in Fig. 7 (c), it shows that it is the $\mathrm{B}$ factor influencing the $\mathrm{S} / \mathrm{N}$ ratio the most and the $\mathrm{C}$ factor influencing the $\mathrm{S} / \mathrm{N}$ least. As it is the main objective of the study to seek the larger-the-better $\mathrm{S} / \mathrm{N}$ ratio, through the above analyses, it is evaluated that the factor combination performing the best $\mathrm{S} / \mathrm{N}$ ratio is $\mathrm{A} 2 \mathrm{~B} 1 \mathrm{C} 1$.

After the analyses conducted according to the three methods, two optimal parameter combinations, A2B1C2 and $\mathrm{A} 2 \mathrm{~B} 1 \mathrm{C} 1$ are derived, the optimal factor combination for quality characteristic factor Analysis was A2B1C2; the standard deviation factor analysis was $\mathrm{A} 2 \mathrm{~B} 1 \mathrm{C} 1$; the $\mathrm{S} / \mathrm{N}$ Ratio Analysis was A2B1C1. Though the analysis of the $\mathrm{S} / \mathrm{N}$ ratio is aimed at integrating the optimized quality characteristics and the least standard deviation, the optimal factor combination of the $\mathrm{S} / \mathrm{N}$ ratio is still a conclusion obtained upon a lot of assumptions. Therefore, further experimental steps for estimation and verification are necessary to confirm that the combination is really the optimal factor combination. In the current study, estimative calculation and experiments of quality characteristic are conducted to $\mathrm{A} 2 \mathrm{~B} 1 \mathrm{C} 1$ to derive the estimative value is 5417.6 seconds while the average operation time in the experiments is 5248.3 seconds. The experimental data of $\mathrm{A} 2 \mathrm{~B} 1 \mathrm{C} 1$ and $\mathrm{A} 2 \mathrm{~B} 1 \mathrm{C} 2$ are compared and the results are shown in Table 2 (a). From Table 2(a), to simply discuss the largest operation time without consideration of stability, $\mathrm{A} 2 \mathrm{~B} 1 \mathrm{C} 2$ is the desired factor combination. If the stability is taken into consideration, the operation time of the Power Supply and Work Module must be sacrificed to achieve the optimized design. Though the factor combination A2B1C1 cannot achieve the largest operation time, it realizes the operation time not far from that of the combination $\mathrm{A} 2 \mathrm{~B} 1 \mathrm{C} 2$, merely $6.87 \%$ less. In respect to the large-the-better $\mathrm{S} / \mathrm{N}$ ratio, the difference between both is around $0.51 \%$, which is a slight difference. Also, since the $\mathrm{C}$ factor does not bring serious influence to the $\mathrm{S} / \mathrm{N}$ ratio, the variation of the $\mathrm{C}$ factor does not affect the quality much. Thus, the study determines that the factor combination of $\mathrm{A} 2 \mathrm{~B} 1 \mathrm{C} 2$ is the optimum factors arrangement for the "Proton Exchange Membrane Fuel Cell Power Supply and Work Module for Tripedal Industrial Robot", as shown in Table 2(b).

TABLE II: COMPARISON BETWEEN A2B1C2 AND A2B1C1 FACTOR
COMBINATIONS
\begin{tabular}{|l|l|l|l|l|l|l|l|l|l|l|l|}
\hline Exp. & A & B & C & yl & y2 & y3 & y 4 & y 5 & Ave & S & Larger-better S/N \\
\hline 1 & 2 & 1 & 2 & 5805 & 5778 & 5278 & 5087 & 5659 & 5521.60 & 319.98 & 74.79 \\
\hline 2 & 2 & 1 & 1 & 5456 & 5239 & 5229 & 5163 & 5234 & 5264.70 & 112.18 & 74.41 \\
\hline
\end{tabular}

(b) Optimum factor arrangement and operation time

\begin{tabular}{|l|l|l|}
\hline A2 & B1 & C2 \\
\hline Volume of The Gas Tank & Electric Load & Initial Pressure Value of The Gas Tank \\
\hline $15268.14 \mathrm{~mm}^{3}$ & $11.67 \Omega$ & $0.189 \cdot \mathrm{N} / \mathrm{m}^{2}$ \\
\hline Operation Time: 5520.9 Sec. & & \\
\hline
\end{tabular}

The Power Supply and Work Module are then installed on a self-made Module-Robot of Hydrogen-based Energy (Fig. 8) so as to observe the operation. Fig. 8 (a) and (b) shows the demonstration of the tripedal industrial robot and the photos of its walking motions. The description of the walking motions of the robot: Through the test of the Module- Tripedal-Robot Product of Hydrogen-based Energy it is found that in a motor-powered robot, for the smoother operation thereof, in addition to changing the motor to a low-voltage-driving motor, two proton exchange membrane cells may be needed to be serially connected to increase the voltage so as to provide more powerful output to the motor for resisting the external resistance occurring when the robot is used. If the module is to be applied to a robot with a sensor, electronic elements are needed to temporarily store power or enhance voltage to meet the rated usage voltage of $5 \mathrm{~V}$. Though applying the "Proton Exchange Membrane Fuel Cell Power Supply and Work Module for Robot" to a robot may need redesigning of the robot or the addition of more electronic elements to enhance use efficiency, it is sure that the module is feasible to the robot. Fig. 8 (c) demonstrates that the walking process of the physical model of the tripedal robot moved forward smoothly, and indicates that hydrogen can be used for the robot.

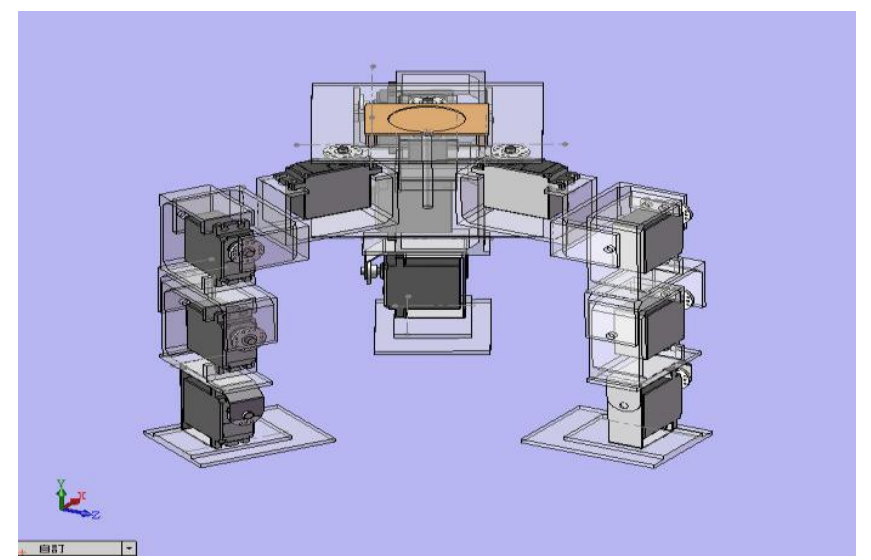

(a) $3 \mathrm{D}$ model construction for tripedal robot.

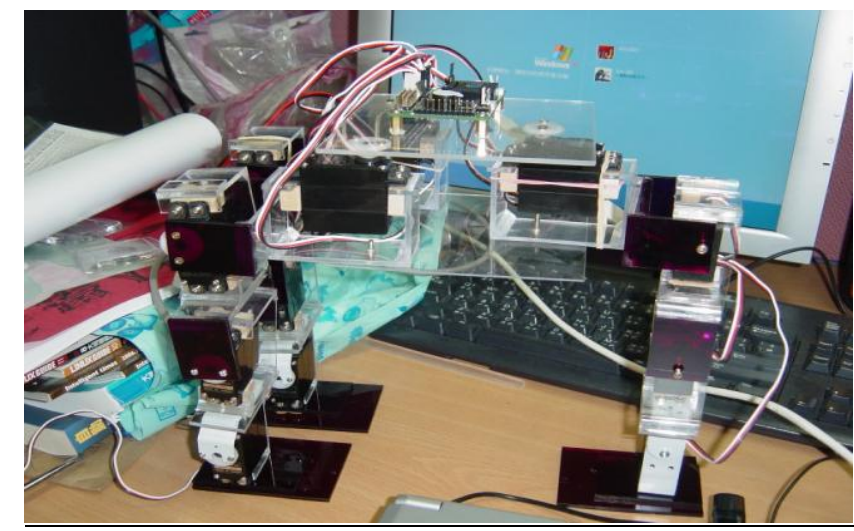

(b) Demonstration of tripedal robot. 


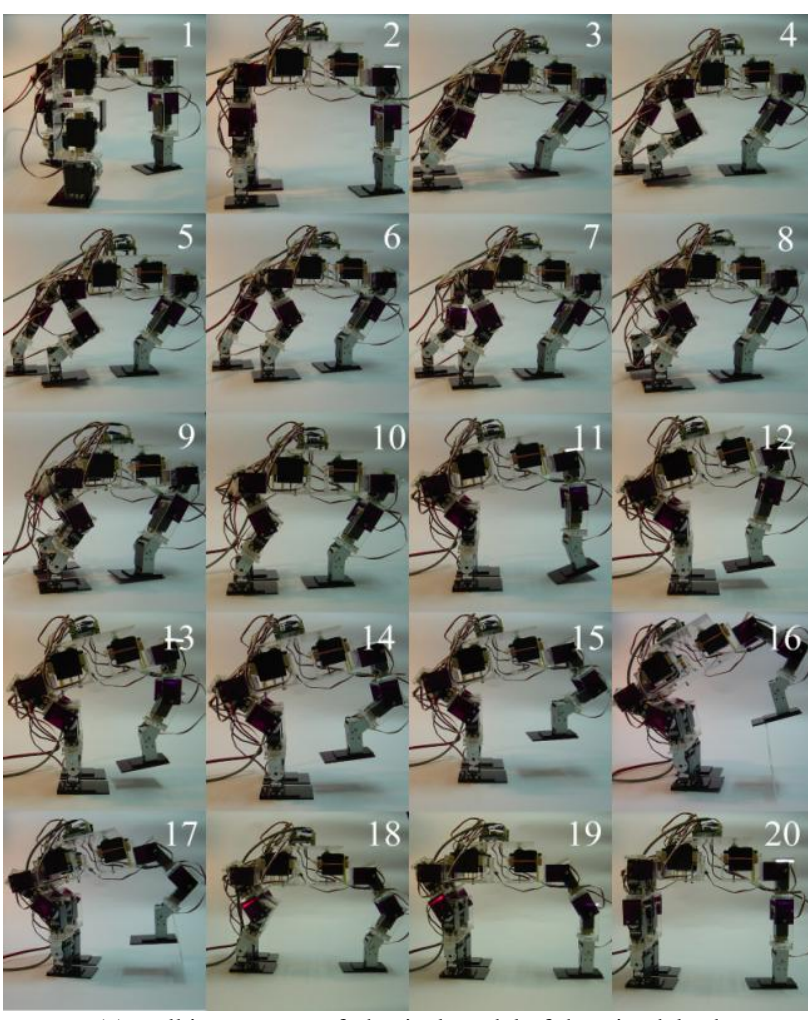

(c) walking process of physical model of the tripedal robot. Fig. 8. Module-robot of hydrogen-based energy.

\section{CONCLUSION}

The brake regeneration control of rotational speed and position will be obtained through Hall sensor or Encoder which generates the regeneration electric current according to the regeneration command. The design electric current controller can control the value of the regeneration electric current on stability. T It consumes a very small amount of kinetic energy to friction loss and regenerates most parts of the kinetic energy as an available energy to increase the contiguous operation by matching the electronic brake and mechanical brake. The Simulink model reflects the actual situation of "Tripedal-Robot" from brake simulation and experiment execution. It also simulates the brake regeneration after adding the brake simulation controller to the motor. This study affectively assists the simulation development for the robots, and also saves on expenses and time. An environmentally friendly hydrogen energy source is also implemented using a "Hydrogen Fuel Cell Battery Module" design to power the "Tripedal-Robot Product" constructed for this research. In the present study, a renewable use mold of the "Hydrogen-based Energy" realized upon the "Proton Exchange Membrane (PEM) Fuel Cells" and "Solar Cells" is constructed and the Taguchi Method is implemented to analyze the "Proton Exchange Membrane Fuel Cell Power Supply and Work Module for Robot" so as to verify that the longest operation time of the "Proton Exchange Membrane Fuel Cell Power Supply and Work Module for Robot". The study assembled the proton exchange membrane fuel cell power supply module in the "Hydrogen-based Energy Module-Robot of Hydrogen-based Energy" and observes its operation state. It finds that the robot moved forward smoothly, and indicates that hydrogen can be used for the robot. This experiment validates the hydrogen energy source as feasible for application in industrial robot design. This research effectively raises the commercial potential for hydrogen- powered robots. "Hydrogen-based Energy" will become applied extensive to the hydrogen- powered industrial robots for the engineering and the manufacturing fields but also makes a contribution in the academic science and environmental education.in the future by way of this study.

\section{ACKNOWLEDGMENT}

This study was supported by the National Science Council, contract 102-2221-E-152-005 and the Ministry of Science and Technology, Taiwan (MOST 104-2221-E-152 005-).

\section{REFERENCES}

[1] P. Pillay and R. Krishnan, "Modeling, simulation, and analysis of permanent-magnet motor drives," IEEE Transactions on Industry Applications, vol. 25, no. 2, pp. 675-690, 1989.

[2] F. Caricchi, F. Crescimbini, C. Giulii, and L. Solero, "Study of bidirectional buck-boost converter topologies for application in electrical vehicle motor drives," in Proc. the Thirteenth Annual Applied Power Electronics Conference and Exposition, vol. 1, pp. 287 $-293,1998$.

[3] R. W. Graham, "Rechargeable batteries, park ridge," N. J.: Noyes Data Corp, 1980.

[4] J. L. Heder, P. A. Budney, and M. G. Andrew, "High specific energy lead-acid battery system for electric vehicle propulsion," in Proc. the 24th Intersociety Energy Conversion Engineering Conference, vol. 3 pp.1647-1651, 1998.

[5] P. Setlur, J. R. Wagner, D. M. Dawson, and B. Samuels, "Nonlinear control of a continuously variable transmission (CVT)," Control Systems Technology, 2003, pp.101-108.

[6] J. Paterson and M. Ramsay, "Electric vehicle braking by fuzzy logic control," in Proc. the Conference Record of the 1993 IEEE Industry Applications Society Annua G.l Meeting, vol. 3, no. 1, pp. 200-204, 1993.

[7] P. Mattavelli, L. Rossetto, G. Spiazziand, and P. Tenti, "General purpose fuzzy controller for DC-DC converters," IEEE Transaction on Power Electronics, vol. 12, no. 1, pp. 79-86, 1997.

[8] R. C. Becerra, T. M. Jahns, and M. Ehsani, "Four-quadrant brushless ECM drive with integrated current regulation," IEEE Transactions on Industry Applications, vol. 28, no. 4, pp. 833 -841, 1992.

[9] U. Kiencke and L. Nielsen, "Automotive control systems for engine driveline and vehicle," Springer ISBN 3-540-66922-1, 2000, pp. $47-$ 52.

[10] Z. C. Liu, "Model analysis and controller design of electric motorcycles," M.Sc. Thesis, National Taiwan University, Taiwan, 2000.

[11] Y. W. Kwon and H. Bang, "The finite element method using," Matlab, CRC Press, New York, 2000.

[12] L. Shanshan, Z. Zhengming, M. Shuo, and C. Jianyun, "A nonlinear analytical model for switched reluctance motor," IEEE Region 10 Conference on Computers, Communications, Control and Power Engineering, 2002, vol. 3, pp. 2034-2037, 2002.

[13] F. R. Salmasi and B. Fahimi, "Modeling switched-reluctance machines by decomposition of double magnetic saliencies," IEEE Trans. Magnetics, vol. 40, no. 3, pp. 1562-1572, 2004.

[14] M. A. Lewis, E. C. Ralph, A. H. Cohen, and M. Hartmann, "Toward biomorphic control using custom a VLSI CPG chips," presented at the 2000 International Conference on Robotics and Automation (ICRA 2000), San Francisco, April 2000.

[15] A. J. Ijspeert, "Central pattern generators for locomotion control in animals and robots: A review," Neural Networks, vol. 21, no. 4, pp. 642-653, 2008.

[16] A. Spröwitz, R. Moeckel, J. Maye, and A. J. Ijspeert, "Learning to move in modular robots using central pattern generators and online optimization," The International Journal of Robotics Research, vol. 27, no. 3-4, pp. 423-443, 2008.

[17] A. Sprowitz, A. Tuleu, M. Vespignani, M. Ajallooeian, E. Badri, and A. J. Ijspeert, "Towards dynamic trot gait locomotion: Design, control, and experiments with cheetahcub, a compliant quadruped robot," International Journal of Robotics Research, vol. 32, no. 8, pp. 933951, 2013. 
[18] A. J. Ijspeert, "Central pattern generators for locomotion control in animals and robots: a review," Neural Networks, vol. 21, no. 4, pp. 642-653, 2008

[19] R. T. Schroer, M. J. Boggess, R. J. Bachmann, R. D. Quinn, and R. E. Ritzmann, "Comparing cockroach and whegs robot body motion," in Proc. the IEEE International Conference on Robotics and Automation, pp. $3288-3293$

[20] S. J. Kim, E. Clark, and M. R. Cutkosky, "iSprawl: Design and tuning for high-speed autonomous open-loop running," The International Journal of Robotics Research, vol. 25, no. 9, pp. 903-912, 2006.

[21] G. Loeb, "Learning from the spinal cord," The Journal of Physiology, 2001, vol. 533, no. 1, vol. 533, no. 1, pp. 111-117, 2001.

[22] S. A. Grigor'ev, Y. R. Alanakyan, and V. N. Fateev, A. V. D Rusanov, "Modeling of the mass transfer in proton-exchangemembrane fuel cells," Dokla dy Physical Chemistry, vol. 382, pp. 3134, 2002.

[23] Q. Wang, D. Song, T. Navessin, S. Holdcroft, and Z. Liu, "A mathematical model and optimization of the cathode catalyst layer structure in PEM fuel cells," J. of Electrochimica Acta, vol. 50, pp. 725-730, 2004

[24] R. Strobel, M. Oszcipok, M. Fasil, B. Rohland, L. Jorissen, and J. Garche, "The compression of hydrogen in an electrochemical cell based on a PE fuel cell design," Journal of Power Sources, vol. 105, no. 2, pp. 208-215, 2002.

[25] T. Ioroi, T. Oku, K. Yasuda, N. Kumagai, and Y. Miyazaki, "Influence of PTFE coating on gas diffusion backing for unitized regenerative polymer electrolyte fuel cells," Journal of Power Sources, 2003, 124, no. 2, pp. 385-389.

[26] Y. Yuan, J. Zhang, C. Lv, and Y. Li, "Design and performance analysis of a novel regenerative braking system for electrified passenger vehicles," SAE Int. J. Mater. Manf, 2016, vol. 9, no. 3, 2016.

[27] B. A. Jones, "Kinematics for multi-section continuum," IEEE Transactions on Robotics, vol. 22, no. 6, pp. 1087-1099, 2006.

[28] T. McGeer, "Passive walking with knees," IEEE International Conference on Robotics and Automation, 1990, pp. 1640-1645.

[29] H. Lim and A. Takanishi, "Compensatory motion control for a biped walking robot," Robotica, vol. 23, pp.1-11, 2005.

[30] Y.W. Lin, "Humanoid recognizing piano scores and playing robots implementation," Master's Thesis, Department of Computer Science and Information Engineering, National Taiwan University of Science and Technology, Taipei, Taiwan, 2010.
[31] D. Zhang, J. Lei, B. Li, D. Lau, and C. Cameron, "Design and analysis of a piano playing robot," in Proc. the 2009 IEEE International Conference on Information and Automation, Zhuhai/Macau, China, 2009, pp. 757-761.

[32] Y. J. Lee and S. Hirose, "Three-legged walking for fault tolerant locomotion of a quadruped robot with demining mission," in Proc. the IEEE/RSJ International Conference on Intelligent Robots and Systems.

[33] S. Martel, M. Sherwood, C. Helm, and W. G. D. Quevedo, "Threelegged wireless miniature robots for mass-scale operations at the subatomic scale," in Proc. IEEE International Conference on 2001 ICRA vol. 4, pp. 3423-3428, 2001

[34] R. Sreenivas, R. S. Rao, K. Prakasham, P. S. Krishna, P. N. Rajesham, L. Sarma, R. Venkateswar, and R. Xylitol, "Production by Candida sp.: parameter optimization using Taguchi approach," Process Biochemistry, vol. 39, pp. 951-95, 2004.

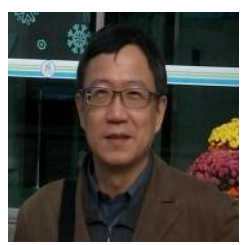

P. S. Pa is a professor in the Department of Digita Content Design and the Graduate School of Toy and Game Design at the National Taipei University of Education. He won his doctorate of Powe Mechanical Engineering from the National Tsing Hua University, and was elected as a faculty merit pay honor member of Ministry of Education and the project chairman of "High Efficiency Advanced Power Generation System of Green Energy Technology". Prior to his position at the National Taipei University of Education, he was a works supervisor of products design and manufacturing. His fields of interest are innovative design and manufacturing processes. His current research includes flat panel displays (FPD), ECM processes, precision manufacturing processes, Nano Technology, MEMS, toy and game design, interactive installation art, robots, green energy resources, and semiconductor and electro-optical engineering. $\mathrm{He}$ is an active researcher of science and engineering, with areas of specialty including teaching of digital content design, user interface, human-computer interaction and different engineering methods. Moreover, he has conducted science education workshops and teachers' trainings internationally. Furthermore, he has been publishing and presenting numerous book chapter, articles, research papers and conference papers in engineering technology internationally. 